\section{References}

1 Reid DD. The beginnings of bronchitis. Proceedings of the Royal Society of Medicine 1969;62: 311-6.

2 Barker DJP, Osmond C. Childhood respiratory infection and adult chronic bronchitis in England and Wales. Br Med f 1986;293:1271-5.

3 Colley JRT, Reid DD. The urban and social origins of childhood bronchitis in England and Wales. BrMed f 1970;ii:213-7.

4 Burrows B, Knudson RJ, Lebowitz MD. The relationship of childhood respiratory illness to adult obstructive airways disease. Am Rev Respir Dis 1977;115:751-60.

5 Colley JRT, Douglas JWB, Reid DD. Respiratory disease in young adults: influence of early childhood lower respiratory tract illness, social class, air pollution, and smoking. $\mathrm{Br} \mathrm{Med} \mathcal{J}$ 1973;iii:195-8.

6 Kiernan KE, Colley JRT, Douglas JWB, Reid DD. Chronic cough in young adults in relation to smoking habits, childhood environment and chest illness. Respiration 1976;33:236-44.

7 Britten N, Wadsworth J. Long term respiratory sequelae of whooping cough in a nationally representative sample. BrMed f 1986;292:441-4.

representative sample. Br Med f 1986;292:441-4.
8 Harnett RWF, Mair A. Chronic bronchitis and the catarrhal child. Scot Med f 1963;8:175-84.

8 Harnett RWF, Mair A. Chronic bronchitis and the catarrhal child. Scot Med f 1963;8:175-84. asthma in children. An epidemiological study. Br Med f 1969;iv:321-5.

10 Martin AJ, McLennan LA, Landau LI, Phelan PD. Natural history of childhood asthma to adult life. BrMed F 1980;280:1397-1400.

11 Martin AJ, Landau LI, Phelan PD. Lung function in young adults who had asthma in childhood. Am Rev Respir Dis 1980;122:609-16.

12 Martin AJ, Landau LI, Phelan PD. Asthma from childhood at age 21: the patient and his disease. BrMed f 1982;284:380-2.

13 Phelan PD. Does adult chronic obstructive lung disease really begin in childhood? $\mathrm{Br} \mathcal{F}$ Dis Chest 1984;78:1-9.

14 Butler NR, Bonham DG. Perinatal mortality. First report of the 1958 British perinatal mortality survey, under the auspices of the National Birthday Trust Fund. Edinburgh: Livingstone, 1963.

survey, under the auspices of the National Birthday Trust Fund. Edinburgh: Livingstone, 1963.
15 Davie $\mathrm{R}$, Butler N, Goldstein H. From birth to seven. The second report of the national child development study (1958 cohort). London: Longman, 1972.

16 Fogelman K, ed. Britain's sixteen-year-olds. London: National Children's Bureau, 1976.

17 Fogelman K, ed. Growing up in Great Britain: papers from the national child development study. London: MacMillan, 1983.

18 Shepherd P. The national child development study; an introduction to the origins of the study and the methods of data collection. London: NCDS User Support Group, City University, 1986.
19 Medical Research Council. Questionnaire on respiratory symptoms. London: Medical Research Council, 1966.

20 Medical Research Council Committee on the Aetiology of Chronic Bronchitis. Definition and classification of chronic bronchitis for clinical and epidemiological purposes. Lancet 1965; ; classificat $775-9$.

21 Baker RJ, Nelder JA. The GLIM system manual. Release 3. Oxford: Numerical Algorithms Group, 1978.

22 Anderson HR, Bland JM, Patel S, Peckham C. The natural history of asthma in childhood. J Epidemiol Community Health 1986;40:121-9.

23 Strachan DP. The childhood origins of adult bronchitis in a British cohort born in 1958 (the national child development study). London: School of Hygiene and Tropical Medicine, University of London, 1986. $123 \mathrm{pp}$. (MSc thesis.)

24 Watkins CJ, Burton P, Leeder S, Sittampalam Y, Wever AJM, Wiggins R. Doctor diagnosis and maternal recall of lower respiratory illness. Int $\mathcal{F}$ Epidemiol 1982;11:62-6.

25 Goodall JF. The natural history of some common respiratory infections in children and some principles in its management. III: Wheezy children. $\mathcal{F}$ R Coll Gen Pract 1958;1:51-9.

26 Fry J. Acute wheezy chests. Br Med $\mathcal{J} 1961$; i:227-32.

27 Strachan DP. The prevalence and natural history of wheezing in early childhood. $\mathcal{R}$ R Coll Gen Pract 1985;35:182-4.

28 Woolcock AJ, Peat JK, Salome CM, et al. Prevalence of bronchial hyperresponsiveness and asthma in a rural adult population. Thorax 1987;42:361-8.

29 Corrao WM, Braman SS, Irwin RS. Chronic cough as the sole presenting manifestation of bronchial asthma. N Engl f Med 1979;300:633-7.

30 Anderson HR. Respiratory disease in childhood. Br Med Bull 1986;42:167-7

31 Johnston IDA, Anderson HR, Lambert HP, Patel S. Respiratory morbidity and lung function after whooping cough. Lancet 1983;ii:1104-8.

32 Mok JYQ, Simpson $\mathrm{H}$. Outcome for acute bronchitis, bronchiolitis and pneumonia in infancy. Arch Dis Child 1984;59:306-9.

33 McConnochie KM, Roghmann KJ. Bronchiolitis as a possible cause of wheezing in childhood: new evidence. Pediatrics 1984;74:1-10.

34 Peto $\mathrm{R}$, Speizer FE, Cochrane AL, et al. The relevance in adults of airflow obstruction, but not of mucus hypersecretion, to mortality from chronic lung disease. Am Rev Respir Dis 1983;128: $491-500$

35 Britten N, Davies JMC, Colley JRT. Early respiratory experience and subsequent cough and peak expiratory flow rate in 36 year old men and women. BrMed $\mathcal{F}$ 1987;294:1317-20.

(Accepted 1 December 1987)

\title{
Risk of acute non-specific upper respiratory tract infections in healthy men taking dapsone-pyrimethamine for prophylaxis against malaria
}

\author{
PHENG SOON LEE, EDWIN Y L LAU
}

\begin{abstract}
The relative risks of non-specific upper respiratory tract infections were studied in two well matched groups of military recruits to see whether dapsone-pyrimethamine (Maloprim) given as antimalarial prophylaxis was associated with immunosuppression. Mean risks of upper respiratory tract infection were $64 \%$ higher in the study group than in the controls, the largest monthly differences being recorded in the months of harder training. These findings were unlikely to have been due solely to harder training in the study group, as concurrently measured sprains (arguably more likely to have been affected) were increased by only $19 \%$. A more likely explanation was some degree of immunosuppression, physical stress possibly having a synergistic effect.

These findings suggest that travellers taking dapsone-pyrimethamine as antimalarial prophylaxis may be rendered more susceptible to commoner infections, especially when engaged in increased physical activity.
\end{abstract}

Headquarters Medical Services, Singapore Armed Forces, Singapore PHENG SOON LEE, MB, BSC, formerly staff officer in charge of preventive medicine

EDWIN Y L LAU, BSC, formerly graduate researcher, preventive medicine branch

Correspondence to: Dr Lee Pheng Soon, 4 Fourth Lokyang Road, Singapore 2262.

\section{Introduction}

Severe adverse reactions to antimalarials have been reported in previously normal people, some resulting in death or serious morbidity. Nineteen cases (six fatal) of severe cutaneous reactions were recorded among American travellers taking pyrimethaminesulfadoxine (Fansidar) with chloroquine, ${ }^{1}$ and agranulocytosis has been reported in people taking dapsone-pyrimethamine (Maloprim). ${ }^{2}$ Many authorities therefore recommend that a riskbenefit analysis should always be done before prescribing these drugs, especially for prophylactic use, the latest and most elegantly argued case being that presented by Peto and Gilks. ${ }^{3}$ This, however, implies the existence of accurate information concerning risks from less dramatic but probably more frequent unwanted effects, which are far more difficult to document than serious reactions even if suspected. Any study designed to establish these "minor" events scientifically would need to be conducted on a scale too large ethically to justify enrolling the necessary numbers of healthy volunteers outside a malarious zone. On the other hand, field trials are justifiable where there is definite risk of infection but control groups cannot be identified because prophylaxis cannot be withheld. Thus only uncontrolled field trials remain; and these often cannot detect small differences occurring in a minority of the population studied.

These difficulties have almost completely prevented study of the immunopharmacology of antimalarials in man, which is of increasing importance given the frequent use of these drugs in this age of widespread global travel. Most doctors have at one time or another been approached for prescriptions of such prophylactic drugs, often 
by casual tourists just before departure for some exotic tropical destination. Almost all existing data suggesting immunosuppressive properties of antimalarial drugs, however, have been from animal studies, most using drug concentrations much higher than in normal clinical practice..$^{47}$

One recent study of immunoglobulins in a small group of healthy people after a short period of prophylaxis with dapsonepyrimethamine at normal recommended doses found post-treatment concentrations of IgG and $\operatorname{IgM}$ within "normal" limits, though significantly lower than pretreatment values. ${ }^{8}$ No meaningful correlation of these immunological findings with the prevalence of concurrent infections was possible, however, because no control population existed. The probability of clinically significant immunosuppression occurring with this drug combination was thus suggested but remained uncertain.

Clarification of this point is especially important to many doctors in South East Asia, where local patterns of resistance to other drugs have often made dapsone-pyrimethamine a prophylactic of first choice. We report the results of a unique natural experiment. A large group of military recruits, each taking dapsone-pyrimethamine for antimalarial prophylaxis over three months, was matched with another, very similar group near by, not given any prophylactic drug. We investigated the possibility of clinically significant immunosuppression associated with the drug combination by comparing risks of acute non-specific upper respiratory tract infections in both populations. The extent to which this index may also have been influenced by differences in intensity of training both between and within each of the two groups was investigated by comparing risks of concurrently occurring sprains.

\section{Subjects and methods}

Recruits in the Singapore armed forces are trained in several camps, but antimalarial prophylaxis is used routinely only in one located close enough to islands outside territorial Singapore for malaria to be a possibility. Sporadic cases had occurred near there in past years, even after Singapore had been declared malaria free by the World Health Organisation. All recruits in this camp thus took dapsone-pyrimethamine (Maloprim) as a routine measure.

The study group comprised all 8337 military recruits who had lived at the camp for three months during 1984 to mid-1985. The control group comprised 11220 recruits who had trained simultaneously at a camp less than $15 \mathrm{~km}$ away. Controls were selected from the groups available as being the closest match to the study group on the basis of activity and racial composition. They would have been performing the same training tasks, following the same training syllabus (possibly even on the same day) as the study group. All recruits were healthy males aged 17-18 who had been declared free of major illnesses during routine medical screening before enlistment. About three quarters were Chinese and the remainder a mixture of Malays, Indians, Eurasians, and Whites, a racial mix almost exactly that of the general population of Singapore.

There were three main differences between the study group and controls. Firstly, the study group took dapsone-pyrimethamine (one tablet once a week throughout the study period). Secondly, all members of the study group were officer cadet candidates and probably were drilled harder at the same training tasks than the controls. Lastly, all members of the study group were rated as combat fit (a requirement of officer cadets) compared with only $84 \%$ of the controls.

Both camps were at sea level and had similar, reasonably well drained training grounds. Food, housing, and medical facilities (a centralised medical centre in each camp, manned round the clock by at least one resident medical officer from whom recruits were permitted to seek medical attention without restriction) were also almost identical.

Risks of disease-that is, defined as the probability of any one recruit falling ill from that disease during one month of training - were calculated by personal inspection of the records of patients seen in each medical centre. The risk of upper respiratory tract infection was chosen as a representative index reflecting general ability to resist common infections, as this disease was both frequent and unlikely to have been misdiagnosed. Almost all cases recorded were common colds or acute coryza, pharyngitis, or tonsillitis. Asthma, chronic conditions (for example, sinusitis or vasomotor rhinitis), and acute infections of the lower respiratory tract (for example, bronchitis, bronchiolitis, or pneumonia) were specifically excluded from our classification.

As risks of upper respiratory tract infection might conceivably also have been affected by the comparatively more rigorous physical training of the officer cadets, we studied risks of concurrently occurring sprains, which were far more likely to have been affected by intensity of training. Most of these were soft tissue or ligamentous injuries of limb or back muscles. Any differences in risk of sprains between the two groups would suggest harder training in one group, and any differences in risk between any two months within the same group would suggest that one part of the course was more difficult physically than another. For example, a difference in the intensity of physical training may have occurred in the first part of the course because of attempts to "toughen" the recruits in as short a time as possible. Thus both overall and monthly risks were calculated.

Differences in probabilities were tested for by computing the sample odds ratio as described by Fleiss. ${ }^{9}$ This ratio indicates the risk of a subject in the study group falling ill from a disease relative to the risk in his control in the presence of an antecedent factor (antimalarial prophylaxis). In the absence of influence by the antecedent factor the odds ratio would be expected to be roughly $1 \cdot 0$. The $99 \cdot 9 \%$ confidence intervals (where we could reasonably expect the population statistic to be found) were also calculated; whether these included the expected "null" odds ratio of 1.0 thus indicated lack of significance or otherwise.

\section{Results and discussion}

Tables I and II and figures 1 and 2 show the risks of sprains and upper respiratory tract infections recorded in the two groups during the three months of training. There were clear differences between the two groups, the overall risk of upper respiratory tract infection being $64 \%$ higher in the study group compared with the controls $(0.324 v 0.198)$ and the largest differences occurring in the months of harder training. The overall risk of sprains was increased by $19 \%$ in the study group compared with the controls $(0.233 v 0 \cdot 196)$.

TABLE I-Risks of upper respiratory tract infection in study and control groups of recruits during first, second, and third months of training

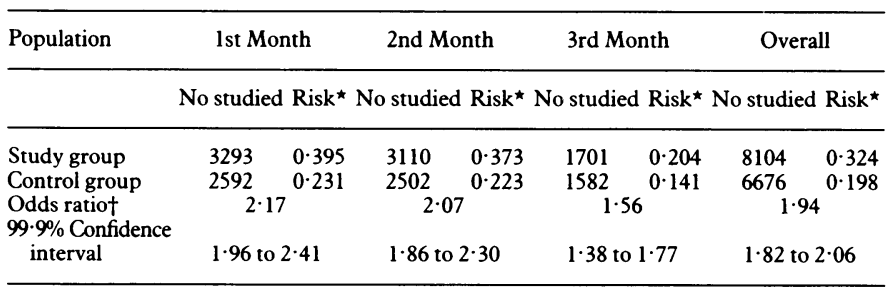

$\star_{\text {Risk }}=$ Sample probability or risk (per man per month of training).

tOdds ratio= Risk of illness in study group relative to risk in controls. ${ }^{9}$

TABLE II-Risk of sprains in study and control groups of recruits during first, second, and third months of training

\begin{tabular}{|c|c|c|c|c|c|c|c|c|}
\hline \multirow[t]{2}{*}{ Population } & \multicolumn{2}{|c|}{ lst Month } & \multicolumn{2}{|c|}{ 2nd Month } & \multicolumn{2}{|c|}{ 3rd Month } & \multicolumn{2}{|c|}{ Overall } \\
\hline & No studied & Risk & No studied & Risk & No studied & Risk & No studied & Risk \\
\hline \multirow{4}{*}{$\begin{array}{l}\text { Study group } \\
\text { Control group } \\
\text { Odds ratio } \\
99 \cdot 9 \% \text { Confidence } \\
\text { interval }\end{array}$} & 2393 & 0.287 & 1959 & 0.235 & 1467 & 0.176 & 5819 & 0.233 \\
\hline & 2816 & 0.251 & 1997 & $0 \cdot 178$ & 1773 & $0 \cdot 158$ & 6586 & $0 \cdot 196$ \\
\hline & \multicolumn{2}{|c|}{$1 \cdot 20$} & \multicolumn{2}{|c|}{1.49} & \multicolumn{2}{|c|}{$1 \cdot 14$} & \multicolumn{2}{|c|}{1.25} \\
\hline & \multicolumn{2}{|c|}{1.08 to 1.34} & \multicolumn{2}{|c|}{1.26 to 1.60} & \multicolumn{2}{|c|}{1.00 to 1.29} & \multicolumn{2}{|c|}{1.17 to 1.33} \\
\hline
\end{tabular}

In this study only three important variables were unsatisfactorily controlled for: proportions of combat fit personnel, differences in intensity of training, and the use of dapsone-pyrimethamine. We excluded the first from our considerations, as a fitter study group should logically have a lower risk of upper respiratory tract infection and any bias would only have supported the null hypothesis. The control group considered by itself would thus have only one of the remaining two variables uncontrolled for-namely, the intensity of training in the first half of the course. Analysis of data from this group should therefore suggest how differences in the intensity of training might have affected recorded risks of both upper respiratory tract infection and sprains. Subsequent comparison of the data on 
the study disease (upper respiratory tract infection) between the study and control groups may then be done more meaningfully by using the information on risks of sprains as a crude index of the effects of harder training on upper respiratory tract infection in the study group.

Analysis of the data showed that the overall risks of upper respiratory tract infection and sprains were very similar in the controls $(0.198$ and 0.196 respectively; tables I and II). Furthermore, the highest and lowest monthly risks of both conditions coincided with the months of hardest and lightest training - that is, the first and third months respectively (fig 1). Intermediate values

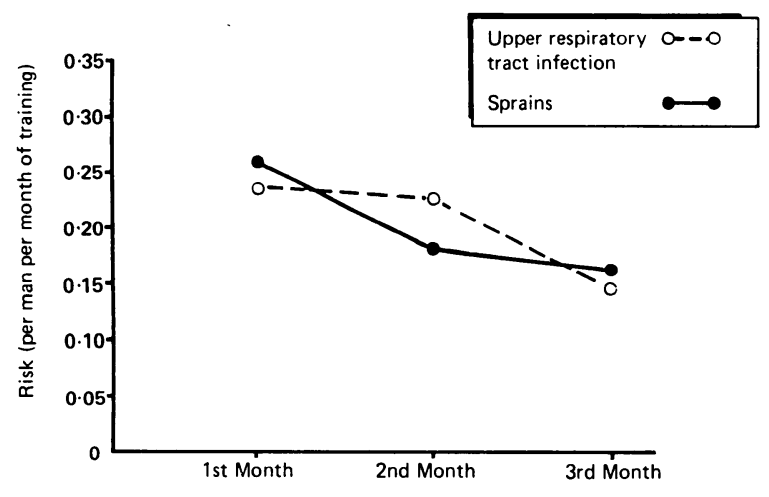

FIG 1-Monthly risks of upper respiratory tract infections and sprains in control group.

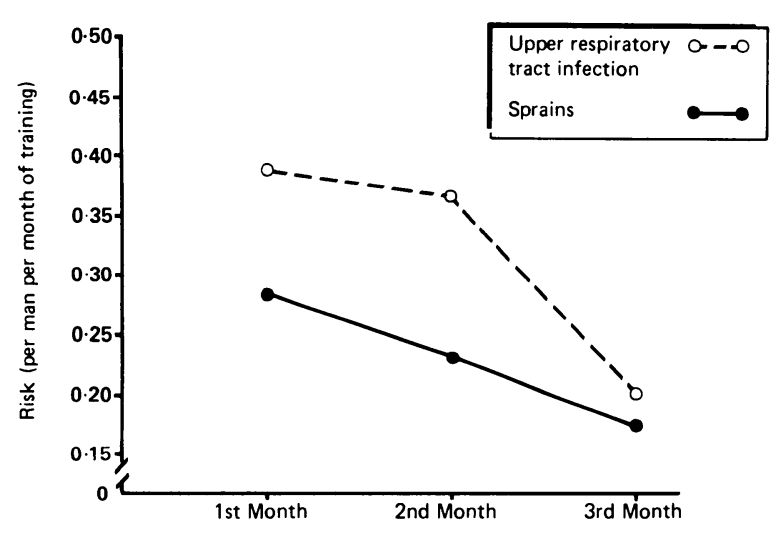

FIG 2-Monthly risks of upper respiratory tract infections and sprains in study group.

were recorded in the second month. Finally, as expected, the risk of sprains improved much more quickly than upper respiratory tract infection when training eased after the first month (fig 1). Thus we concluded that for military recruits training under these conditions and without using prophylaxis the risk of either upper respiratory tract infection or a sprain was very similar and that harder training would increase the risks of both conditions by roughly the same extent.

As the study group of officer cadets generally trained harder than the controls throughout the course, we expected higher but roughly equal risks of both conditions to be found in the study group. The overall risk of sprains was indeed higher than in the controls (by $19 \%$; table II) and the monthly pattern was also little changed (fig 2). As sprains were extremely unlikely to have been related to the use of dapsone-pyrimethamine, we concluded that the increased risk of sprains was largely (if not entirely) due to harder training in the study group. Given that harder training in the study group had raised the risk of sprains by $19 \%$, we expected similar effects on the risk of upper respiratory tract infection. The increase of $64 \%$ recorded (table I) was therefore too high to be reasonably explained in terms of harder training alone and thus we concluded that the last remaining variable-prophylaxis with dapsone-pyrimethaminewas a probable contributory cause.

\section{Conclusion}

Our findings suggest that the comparatively small decrease in immunoglobulin concentrations seen in normal adults receiving prophylaxis with dapsone-pyrimethamine ${ }^{8}$ may be of clinical relevance; though resultant values may still be within "normal" limits, one result might be decreased resistance to common infections such as upper respiratory tract infection, as was found in this study. Of equal interest in our series was that while the risk of upper respiratory tract infection in the first month was $71 \%$ higher in the study group than the controls (and the second month little different at $67 \%$ ), the risk in the third month was raised by $45 \%$. As prophylaxis was taken throughout, possibly the stress of harder physical training in the earlier part of the course may have had a synergistic effect on the immunosuppressive effect of prophylaxis. Risks in populations not engaged in extremes of physical activity may therefore be smaller. Alternatively, it is also possible that some physiological adaptation may have taken place during the months of continued dapsone-pyrimethamine use.

In view of the lack of comparable data with other prophylactic drugs hasty conclusions about the relative safety of dapsonepyrimethamine should not be made from our results. Possibly the fortuitous combination of circumstances that made this study possible (large control and study groups, both well matched in location and activity and observed simultaneously for several months) may not even be found again. We therefore suggest that our findings by themselves are not sufficient reason to change from dapsone-pyrimethamine as a drug of first choice for antimalarial prophylaxis, especially where local patterns of resistance exist to other drugs. Certainly, the additional risk of upper respiratory tract infection that we found (which may well occur with other prophylactic agents) was minor compared with the increased risk of mortality that might accompany premature change to a less efficacious prophylactic. Rather, we hope that our report will alert both physician and traveller to the possibility of a higher risk of upper respiratory tract infection (and possibly other infections) among users of this drug combination, especially in settings of increased physical activity. The doctor will then be more aware when he examines an ill traveller, while the tourist can be advised to take simple commonsense precautions-for example, avoiding inclement weather or unnecessary physical activity and ensuring adequate rest- to minimise the risks of concurrent infections while benefiting from prophylaxis.

We thank the Chief Medical Officer, Ministry of Defence, Singapore, without whose help and encouragement this paper would not have been published; Miss Tai Bee Choo and Mr Andrew Wong for help in computer analysis and statistics; and the 12 resident doctors in the two army camps, on whose professionalism rested the accuracy of this study.

\section{References}

1 Center for Disease Control. Revised recommendations for preventing malaria in travelers to areas with chloroquine-resistant $\mathrm{P}$ falciparum. MMWR 1985;34:185-90.

2 Bruce-Chwatt LJ, Hutchinson DBA. Agranulocytosis associated with Maloprim. Br Med $\mathrm{f}$ 1984;288:65

3 Peto TEA, Gilks CF. Strategies for the prevention of malaria in travellers: comparison of drug regimens by means of risk-benefit analysis. Lancet 1986;i:1256-60.

4 Hurvitz D, Hirschhorn K. Suppression of in vitro lymphocytic responses by chloroquine NEngl f Med 1965;273:23-6.

5 Thong YH, Ferrante A. Inhibition of mitogen-induced lymphocyte proliferative responses by quinine. Am f Trop Med Hyg 1978;23:354-6.

6 Thong YH, Ferrante A, Rowan-Kelly B. Primaquine inhibits mitogen-induced human lymphocyte proliferative responses. Trans $R$ Soc Trop Med Hyg 1978;72:437-539.

7 Thong YH, Ferrante A, Rowan-Kelly B, O'Keefe DE. Effect of mefloquine on the immune response in mice. Trans $R$ Soc Trop Med Hyg 1979;73:388-90.

$8 \mathrm{Ti} \mathrm{Ty}$, Jacob E, Wee YJ. The effect of dapsone-pyrimethamine on immunoglobulin concentrations in malaria chemoprophylaxis. Trans $R$ Soc Trop Med Hyg 1987;81:245-6. 9 Fleiss JL. Statistical methods for rates and proportions. New York: John Wiley and Sons, 1981.

(Accepted 30 November 1987) 